\title{
Biomarkers and Depression Associated to Type 2 Diabetes A Pilot Study
}

\author{
Ernesto Rosario-Hernández ${ }^{* 1,3}$, Lissette Negrón Marín ${ }^{1}$, Estrella Bacenet ${ }^{1}$, Juan Velázquez De Jesús ${ }^{1}$, Pablo López ${ }^{2}$, \\ and Yasuhiro Yamamura²
}

${ }^{1}$ School of Behavioral and Brain Sciences, Ponce Health Sciences University, USA

${ }^{2}$ AIDS Research Program, USA

${ }^{3}$ Ponce Research Institute, USA

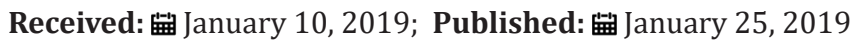

*Corresponding author: Ernesto Rosario Hernández, School of Behavioral and Brain Sciences, Ponce Health Sciences University, USA

\begin{abstract}
Puerto Rico has one of the highest diabetes rates in the USA and the prevalence of clinically diagnosed diabetes increased almost 5 -folds between the years 2000 and 2004; and the upward trend still continues. On the other hand, it is well recognized that depression is highly prevalent among diabetic individuals and both, depression and diabetes, have been associated with the activation of the hypothalamic-pituitary-adrenal (HPA) axis via biomarkers such as cytokines and endotoxins. The purposes of the current cross-sectional study were to compare depression and biomarkers levels between diabetic individuals and a control group. A total of 63 individual participated in the study of which 42 were diabetics and 21 healthy individuals. Results suggest that diabetic individuals shown significant higher depressive symptoms in comparison to individuals in the control group. In terms of the biomarkers' comparison, diabetic individuals had lower levels of various cytokines; also, obtained lower levels of endotoxins. However, diabetic individuals obtained significant higher levels of macrophage-derived chemokine (MDC) and adrenocorticotropic hormone (ACTH), which are related to cortisol release in the (HPA) axis. In terms of practical implications, it is important to examine depression levels on diabetic individuals due to its association to their non-adherence to treatment and the subsequence diabetic complications.
\end{abstract}

Abbreviations: HPA: Hypothalamic-Pituitary-Adrenal; MDC: Macrophage-Derived Chemokine; ACTH: Adrenocortico Tropic Hormone; T2D: Type 2 Diabetes; Hba1c: High Hemoglobin A1c; LPS: Lipopolysaccharide; IRB: Institutional Review Board; RN: Registered Nurse

\section{Introduction}

Diabetes is the seventh leading cause of death in the nation [1]. The Puerto Rico Department of Health report that 3,115 annually die of the disease, making it the third leading cause of mortality in Puerto Rico (a US Commonwealth island in the Caribbean with a population of 3.6 million) where the mortality rate is $81.6 \%$ [2]. Indeed, the CDC report in 2012 showed that $12.7 \%$ of $>18$ years old Puerto Ricans were diabetics, making it one of the highest in the nation [3]. It is well recognized that depressive disorders are highly prevalent among diabetic individuals [4-7]. The condition of type 2 diabetes (T2D) is a chronic illness with established cross- sectional and longitudinal relationships with depression [8]. Moreover, some studies have reported that individuals with T2D have 2.9-fold significantly increased odds of having depression compared to nondiabetes individuals [5-7]. Also, depressive disorders are associated with increased medical morbidity and mortality in individuals with T2D [9]. In addition, there is evidence that individuals with T2D and depression when compared to those without have a higher prevalence of complications, such as retinopathy, nephropathy, among others [10]. Further, depression has been associated with poor adherence to treatment (e.g., diet \& exercise regimens) and poor glycemic control, including, hyperglycemia and high hemoglobin A1c (HbA1c) levels [11-13].

Clinical depression is highly prevalent in diabetes, being up to two times more common among patients with diabetes than those without [4]. Depression in diabetes is not only distressing in and of itself but also consistently associated with poor adherence to selfcare behaviors [14], worse glycemic control [15], complications $[8,9,16]$, and mortality [17]. Further, both diabetes and depression have been related to activation of the HPA axis [18-20]. In this way, HPA axis a regulated system that represents one of the body's mechanisms for responding to acute and chronic stress [21] and it is argue that depression as well as other form of stress such as inflammation via cytokines, activate the HPA axis [22,23]. According to Hänsel, Hong, Cámara and von Känel [24], cytokines 
are regulatory glycoprotein produced by a number of different cell types of which leukocytes are a major source. Circulating levels of cytokines are suitable markers of inflammation since they are produced by activated immune cells and lead to activation of other cells during inflammation. A number of studies have demonstrated that elevated production of some biomarkers such as inflammatory cytokines is associated with the development of depression in patients with chronic diseases [25-31].

There is a meta-analysis reporting significantly higher concentrations of the pro-inflammatory cytokine's TNF-alpha and IL-6 in depressed subjects compared with control subjects [32]. Moreover, one source of inflammation in T2D patients may arise through commensal bacteria derived from the gut, referred to as endotoxins [33]. Endotoxin is derived from lipopolysaccharide (LPS), which represents cell wall fragments of gram-negative bacteria. For example, previous studies have found that individuals with obesity and T2D have elevated circulating levels of endotoxins compared with a healthy group [34]. Further, chronic persistence of endotoxins has been shown to elicit inflammatory responses [35-37] and hyperglycemic conditions [38,39]. Elevated endotoxins have also been shown to lead to insulin resistance and obesity [4]. A seen above, this mechanism of depression and T2D has been relatively of recent interest in some studies mostly separately [4042], but despite the fact that Puerto Rico has one of the highest prevalence of diabetes in the nation and being a high-risk group, this mechanism of depression associated with diabetes has not been examined with a Puerto Rican sample of T2D adult patients. There is a need to understand this mechanism of depression and T2D to reverse the trend of increasing diabetes prevalence. Therefore, the aims of this study were twofold. First, to compare depression levels and second, to compare biomarkers levels (cytokines \& endotoxins) between T2D and a control group composed of apparently healthy individuals.

\section{Materials and Methods}

\section{Study Design and Procedures}

For this pilot study, we implemented a cross-sectional exploratory design using quantitative approach. This pilot study consisted of patients with the condition of T2D, who were at the medical office of an endocrinologist and recruited between July 1, 2015 and March 31, 2016 to participate in the research. Also,

Table 1: Sample characteristics.

\begin{tabular}{|c|c|c|c|}
\hline & Complete & T2D & Control \\
\hline Number of Participants & 63 & 42 & 21 \\
\hline Age (Years) & $54.73 \pm 14.5$ & $60.0 \pm 12.22$ & $44.19 \pm 13.08$ \\
\hline \multicolumn{4}{|l|}{ Sex } \\
\hline Male & $36.5 \%(23)$ & $33.3 \%(14)$ & $42.9 \%(9)$ \\
\hline Female & $63.5 \%(40)$ & $66.7 \%(28)$ & $57.1 \%(12)$ \\
\hline \multicolumn{4}{|l|}{ Marital Status } \\
\hline Single & $7.9 \%(5)$ & $2.4 \%(1)$ & $19.0 \%(4)$ \\
\hline Married & $71.4 \%(45)$ & $71.4 \%(30)$ & $71.4 \%(15)$ \\
\hline
\end{tabular}

Cite this article: Rosario-Hernández E, Negrón Marín L, Bacenet E, De Jesús Velázquez J, López P, and Yamamura Y. Biomarkers and Depression Associated to Type 2 Diabetes A Pilot Study. Biomed J Sci \& Tech Res 13(4)-2019. BJSTR. MS.ID.002437. DOI: 10.26717/ BJSTR.2019.13.002437. 


\begin{tabular}{|c|c|c|c|}
\hline Widowed & $3.2 \%(2)$ & $4.8 \%(2)$ & $0 \%$ \\
\hline Divorced & $11.1 \%(7)$ & $14.3 \%(6)$ & $4.8 \%(1)$ \\
\hline Living Together & $6.3 \%(4)$ & $7.1 \%(3)$ & $4.8 \%(1)$ \\
\hline \multicolumn{4}{|l|}{ Education } \\
\hline Elementary School & $9.5 \%(6)$ & $9.5 \%(4)$ & $9.5 \%(2)$ \\
\hline Middle High School & $1.6 \%(1)$ & $2.4 \%(1)$ & $0 \%$ \\
\hline High School & $39.7 \%(25)$ & $42.9 \%(18)$ & $33.3 \%(7)$ \\
\hline Associated Degree & $25.4 \%(16)$ & $16.7(7)$ & $42.9 \%(9)$ \\
\hline Bachelor's Degree & $19.0 \%(12)$ & $21.4 \%(9)$ & $14.3 \%(3)$ \\
\hline Master's degree & $4.8 \%(3)$ & $7.1 \%(3)$ & $0 \%$ \\
\hline \multicolumn{2}{|c|}{ Time Living with T2D (Years) (Mean \pm SD) } & \multicolumn{2}{|c|}{$11.73 \pm 9.09$} \\
\hline BMI (Mean \pm SD) & $32.59 \pm 8.74$ & $34.89 \pm 9.10$ & $27.99 \pm 5.81$ \\
\hline \multicolumn{4}{|l|}{ BMI Categorized } \\
\hline Normal & $12.7 \%(8)$ & $4.8 \%(2)$ & $28.6 \%(6)$ \\
\hline Overweight & $34.9 \%(22)$ & $26.2 \%(11)$ & $52.4 \%(11)$ \\
\hline Obese & $52.4 \%(33)$ & $69.0 \%(29)$ & $19.0 \%(4)$ \\
\hline
\end{tabular}

\section{Comparison of Depression Levels}

Our first aim of the study was to compare depression levels between T2D patients and the control group. As presented in
Table 2, depression levels were significantly higher in T2D patient than those in the control group, obtaining a medium effect size via Cohen's d [48].

Table 2: Comparison of depression levels by group (T2D/Control).

\begin{tabular}{|c|c|c|c|c|}
\hline Group & $\mathbf{n}$ & Mean (SD) & P Value & Effect Size (Cohen's d) \\
\hline T2D & 42 & $9.48(6.56)$ & $.025^{*}$ & 0.64 \\
\hline Control & 21 & $5.71(5.16)$ & & \\
\hline
\end{tabular}

Note: *significant.

\section{Comparison of Biomarkers}

Our second aim was to compare biomarkers (cytokines \& endotoxins) levels between T2D and the control group. As presented in Table 3, levels of cytokines such as IL-10, TNF-Beta, IL-5, IL-6,
IL-4, and IL-13 were significantly lower in T2D patients than those in the control group. However, T2D patients obtained significantly higher levels of MDC and ACTH, which are related to the secretion of cortisol in the HPA axis [49]. Also, levels of endotoxins were significantly lower in T2D patients than those in the control group.

Table 3: Comparison of biomarker levels by group (T2D/Control).

\begin{tabular}{|c|c|c|c|c|c|c|}
\hline \multirow{2}{*}{ Biomarker } & \multicolumn{2}{|c|}{ T2D (n = 42) } & \multicolumn{2}{|c|}{ Control $(n=21)$} & \multirow{2}{*}{ P Value } & \multirow{2}{*}{ Effect Size (r) } \\
\hline & Mean (SD) & Median & Mean (SD) & Median & & \\
\hline IL-1 Beta & $22.59(25.07)$ & 15.24 & $22.03(22.98)$ & 20.42 & .651 & .06 \\
\hline IL-1RA & 300.39 (305.93) & 203.50 & 404.07 (321.67) & 287.00 & .104 & .20 \\
\hline IL-2 & $17.68(19.51)$ & 8.30 & 13.47 (12.47) & 11.65 & .895 & .02 \\
\hline IL-4 & $13.19(25.13)$ & 2.70 & $18.67(35.96)$ & 3.15 & $.013^{*}$ & .31 \\
\hline IL-5 & $10.40(19.37)$ & 2.56 & 32.51 (54.52) & 5.78 & $.004 *$ & .36 \\
\hline IL-6 & $9.94(17.20)$ & 1.18 & $14.14(19.75)$ & 9.36 & $.002 *$ & .38 \\
\hline IL-7 & $8.45(12.61)$ & 3.05 & $7.52(9.20)$ & 4.70 & .410 & .10 \\
\hline IL-10 & $15.29(19.38)$ & 9.16 & 30.22 (39.29) & 15.97 & $.037^{*}$ & .26 \\
\hline IL-12 & $65.00(82.52)$ & 32.91 & 74.47 (112.08) & 35.22 & .493 & .09 \\
\hline IL-13 & $25.02(53.67)$ & 3.14 & 120.99 (184.67) & 26.54 & $.001^{*}$ & .47 \\
\hline IL-17A & 36.22 (49.99) & 19.43 & $25.97(30.55)$ & 16.06 & .550 & .08 \\
\hline IFN-Gamma & $67.28(91.13)$ & 35.32 & $59.27(68.28)$ & 44.98 & .502 & .08 \\
\hline TNF alpha & $28.29(17.18)$ & 21.80 & $29.80(21.28)$ & 28.35 & 636 & .06 \\
\hline
\end{tabular}

Cite this article: Rosario-Hernández E, Negrón Marín L, Bacenet E, De Jesús Velázquez J, López P, and Yamamura Y. Biomarkers and Depression 


\begin{tabular}{|c|c|c|c|c|c|c|}
\hline TNF-Beta & $52.29(123.51)$ & 5.03 & $265.05(397.88)$ & 63.32 & $.001^{*}$ & .56 \\
\hline MDC & $1028.74(380.80)$ & 1023.50 & $677.33(152.53)$ & 693.00 & $.001^{*}$ & .52 \\
\hline ACTH & $4.92(5.59)$ & 3.96 & $1.34(1.41)$ & 1.01 & $.001^{*}$ & .49 \\
\hline Endotoxins & $1.12(.46329)$ & 1.02 & $2.98(2.79)$ & 1.90 & $.001^{*}$ & .40 \\
\hline
\end{tabular}

Note: *significant.

\section{Discussion}

The aims of this study were to compare levels of depression and biomarkers (cytokines \& endotoxins) between T2D patients and a control group. As results shown, T2D subjects had significantly higher levels of depression symptoms than participants in the control group. Moreover, the effect size was a medium one suggesting that magnitude of depression differences may have a more practical implication. This results are consonant with other studies [5-7] in which T2D subjects also shown higher levels of depression. Of course, this result could be regarded as support for the psychological burden hypothesis [50], which states that the burden of knowing that you have diabetes and having a chronic illness to manage, or complications to cope with contributes to higher levels of depression. In our sample of T2D, the average time living with the condition was 11.73 years, as such, diabetes complications are more likely to be found in people with longstanding diabetes [51,52], and in the current sample of T2D subjects, $64.7 \%$ reported at least one diabetes related complication. Nevertheless, some studies results suggest that diabetes alone do not increase manifestation of depression, but having diabetes and complications related to diabetes did [53,54]. However, there are studies that have found that depression symptomatology increased two years after diagnosis without any diabetes related complication [55].

In terms of biomarkers, T2D participants obtained significant lower levels of cytokines, specifically, IL-4, IL-5, IL-6, IL-10, IL-13, and TNF-Beta. These results contrast a large body of literature supporting the hypothesis that diabetes is associated with higher levels of inflammation [56-60]. Nevertheless, other studies have found reduced levels of cytokines, specifically, IFN-alpha on diabetic subjects compared to controls [61]. Conversely, some studies have focused more on the role of inflammatory processes in the development and progression of T2D and have found elevation of cytokines in apparently healthy individuals who later go to develop T2D [62-64], suggesting that inflammation occurs early during the period of impaired glucose tolerance, prior to the diagnosis of T2D. In the current study is notable that $52.4 \%$ and $19.0 \%$ of our sample of apparently healthy individuals were categorized as overweight and obese, respectively, which probably may explain partially the results regarding biomarkers. In contrast, T2D participants obtained higher significant levels of MDC and ACTH, which are related to cortisol release in the HPA axis. Some crosssectional studies have found an elevation of cortisol levels in T2D patients when compare to healthy control subjects [65-67]. While other studies specifically have shown that T2D participants have an elevation of ACTH [68, 69]. Thus, Chiodini et al. [70] suggest that HPA axis activity is enhanced in T2D patients with chronic complications and the degree of cortisol secretion is directly associated with the presence and the number of diabetes related complications, as mentioned before, in the current sample of T2D, $64.7 \%$ has at least one complication, which somehow support the notion of the association between diabetes and the cortisol release in the HPA axis via MDC and especially ACTH.

On the other hand, T2D participants obtained significant lower levels of endotoxins, which contrast with some studies [34] that found that endotoxin levels were significant elevated in T2D patients when compared to non-diabetic subjects. Nevertheless, our results concur with some studies, which have found significantly lower levels of endotoxins $[71,72]$ and they argue that composition of the intestinal microbiota in adults with T2D was different than non-diabetic adult individuals. At the same time, $\mathrm{Al}$ Attas et al. [40] found that serum endotoxin levels were higher on T2D subjects treated with insulin when compared to non-diabetic participants; however, T2D subjects treated with oral medications, such as metformin and rosiglitazone, obtained significantly lower levels of endotoxins than the other groups. In this way, $50 \%$ of the T2D patients reported that they were receiving oral treatment for their diabetic condition, which may explain somehow that T2D patients obtained lower levels of endotoxins. Nevertheless, Munck, Guyre and Holbrook [73] argue that inadequate responses by some allostatic systems trigger compensatory increases in others. If cortisol secretion does not increase in response to stress, secretion of inflammatory cytokines, which usually down-regulated by cortisol, increases, with potentially pathophysiological effects. However, in the case of the current study apparently occurred the opposite where cortisol was elevated and due to this, cytokines and endotoxins were reduced as a response to this unbalance in the allostatic system. Nonetheless, the suggested role of HPA axis dysregulation in both depression and T2D provides a plausible common link between the two disorders [74] and the results of the current study somehow support this notion.

Some limitations of this study include the use of a convenience sample of T2D patients from only one endocrinologist medical office, which is not representative of the majority of T2D patients in Puerto Rico. We were not able to matched T2D patients with control subject in terms of BMI, which is a factor to be considered because may have an effect when comparing cytokines level. In addition, the sample was relatively small, which also limits the use of other statistical analysis, such as logistic regression. Finally, the study cross-sectional design impedes to draw cause and effect conclusion of the findings. However, despite these limitations, this study is, to our understanding, the first in Puerto Rico to examine mechanism of depression in T2D adult patients via the activation of the HPA axis having as biomarkers such as cytokines and endotoxins. 
However, there is still a need for research to better understand this mechanism of depression in T2D patients using biomarkers; therefore, a larger sample is needed to examine the importance of these biomarkers due to, for example, the large number of cytokines and their particular functions. Moreover, a larger sample will allow the use other statistics such as logistic regression to better understand the association of these biomarkers in the mechanism of depression related to T2D.

\section{Conclusion}

Depression symptoms were higher in T2D patients than individuals in the control group, which suggest that it is important to examine depression in T2D patients due to its implications in treatment adherence, self-care, and complications. In terms of biomarkers, results provide support of the activation of the HPA axis in T2D and depression symptomatology since T2D patients obtained lower levels of cytokines and endotoxins; however, T2D obtained higher levels in MDC and ACTH, which probably was due to an unbalance in the allostatic system.

Author Contributions: Conceptualization, E.R.-H., L.N.M., and Y.Y.; Methodology, E.R.-H., L.N.M., and Y.Y; Formal Analysis, E.R.-H. and P.L.; Investigation, E.R.-H., L.N.M., E.B., J.V.D.; Writing-Original Draft Preparation, E.R.-H. and Y.Y.; Writing-Review \& Editing, E.R.-H.; Supervision, E.R.-H. and L.N.M.; Funding Acquisition, E.R.-H.

\section{Funding}

"The project described was supported by the RCMI Program Award Number G12MD007579 from the National Institute on Minority Health and Health Disparities. The content is solely the responsibility of the authors and does not necessarily represent the official views of the National Institutes of Health".

\section{Acknowledgment}

We want to express our gratitude to all diabetic patients and healthy individuals participating in the study and to Dr. Alejandra Santiago Vives, who allowed and helped us recruit her patients from her endocrinology medical office.

\section{Conflicts of Interest}

The authors declare no conflict of interest. The founding sponsors had no role in the design of the study; in the collection, analyses, or interpretation of data; in the writing of the manuscript, and in the decision to publish the results.

\section{References}

1. (2008) Centers for Disease Control and Prevention. State-specific incidence of diabetes among adults-participating States 1995-1997 and 2005-2007. MMWR 57(43): 1169-1173.

2. (2014) Department of Health of Puerto Rico.

3. Geiss LS, Li Y, Kirtland K, Barker L, Burrows, et al. (2012) Increasing Prevalence of Diagnosed Diabetes - United States and Puerto Rico, 1995-2010. Morbidity and Mortality Weekly Report 61(45): 918-921.

4. Ali S, Stone MA, Peters JL, Davies MJ, Khunti K, et al. (2006) The prevalence of co-morbid depression in adults with type 2 diabetes: a systematic review and meta-analysis. Diabetic Medicine 23(11):11651173.
5. Anderson RJ, Freedland KE, Clouse RE, Lustman PJ (2001) The prevalence of comorbid depression in adults with diabetes. Diabetes Care 24(6): 1069-1078.

6. Nouwen A, Nefs G, Caramlau I, Connock M, Winkley K, et al. (2011) Prevalence of depression in individuals with impaired glucosemetabolism or undiagnosed diabetes: a systematic review and meta- analysis of the european depression in diabetes (EDID) research consortium. Diabetes Care 34(3): 752-762.

7. Nouwen A, Winkley K, Twisk J, Lloyd CE, Peyrot M, et al. (2010) European depression in diabetes (EDID) research consortium. Type 2 diabetes mellitus as a risk factor for the onset of depression: a systematic review and meta-analysis. Diabetologia 53(12): 2480-2486.

8. Alvarez A, Faccioli J, Guinzboug M, Castex MM, Bayon C, et al. (2013) Endocrine and inflammatory profiles in type 2 diabetic patients with and without major depressive disorder. BMC Research Notes 6: 61.

9. De Groot M, Anderson R, Free dland KE, Clouse RE, Lustman PJ, et al. (2001) Association of depression and diabetes complications: a metaanalysis. Psychosomatic Medicine 63(4): 619-630.

10. Lin EHB, Heckbert SR, Rutter CM, Katon WJ, Ciechanowski p, et al. (2009) Depression and increased mortality in diabetes: unexpected causes of death. Annals of Family Medicine 7(5): 414-421.

11. Roy MS, Roy A, Affouf M (2007) Depression is a risk factor for poor glycemic control and retinopathy in African-Americans with type 1 diabetes. Psychosomatic Medicine 69(6): 537-542.

12. Van Tilburg MA, McCaskill CC, Lane JD, Edwards CL, Bethel A, et al. (2001) Depressed mood is a factor in glycemic control in type 1 diabetes. Psychosomatic Medicine 63(4): 551-555.

13. Lustman PJ, Griffith LS, Freedland KE, Clouse RE (1997) The course of major depression in diabetes. General Hospital Psychiatry 19(2): 138143.

14. Gonzalez JS, Peyrot M, McCarl LA, Collins EM, Serpa L, et al. (2008) Depression and diabetes treatment nonadherence: a meta-analysis. Diabetes Care 31(12): 2398-2403.

15. Lustman PJ, Anderson RJ, Freedland KE, de Groot M, Carney RM, et al. (2000) Depression and poor glycemic control: a meta-analytic review of the literature. Diabetes Care 23(7): 934-942.

16. Gonzalez JS, Vileikyte L, Ulbrecht JS, Rubin RR, Garrow AP, et al. (2010) Depression predicts first but not recurrent diabetic foot ulcers. Diabetologia 53(10): 2241-2248.

17. Katon WJ, Rutter C, Simon G, Lin EH, Ludman E, et al. (2005) The association of comorbid depression with mortality in patients with type 2 diabetes. Diabetes Care 28(11): 2668-2672.

18. Chiodini I, Di Lembo S, Morelli V, Epaminonda P, Coletti F, et al. (2006) Hypothalamic-pituitary-adrenal activity in type 2 diabetes mellitus: role of autonomic imbalance. Metabolism Clinical and Experimental 55(8): $1135-1140$.

19. Pariante CM, Lightman SL (2008) The HPA axis in major depression: Classical theories and new developments. Trends Neurosci 31(9): 464468.

20. Tresa Anto G (2016) Hypothalamo-Pituitary-Adrenal (HPA) axis and diabetes. International Journal of Nursing Education and Research 4: 393-395.

21. Golden SH, Wand GS, Malhotra S, Kamel I, Horton K (2011) Reliability of hypothalamic-pituitary-adrenal axis assessment methods for use in population-based studies. Eur J Epidemiol 26(7): 511-525.

22. Chrousos GP (1995) The hypothalamic-pituitary-adrenal axis and immune-mediated inflammation, N Engl J of Med 332(20): 1351-1362.

23. Tsigos C, Chrousos GP (2002) Hypothalamic-pituitary-adrenal axis, neuroendocrine factors and stress. J Psychosom Res 53(4): 865-871. 
24. Hänsel A, Hong S, Cámara RJ, von Känel R (2010) Inflammation as a psychophysiological biomarker in chronic psychological stress. Neurosci Biobehav Rev 35(1): 115-121.

25. Dinarello CA (2011) Interlelukin-1 in the pathogenesis and treatment of inflammatory diseases. Blood 117(14): 3720-3732.

26. Lanquillon S, Krieg JC, Bening Abu Shach U, Vedder H (2000) Cytokine production and treatment response in major depressive disorders. Neuropsychopharmacol 22(4): 370-379.

27. Garlanda C, Anders HJ, Mantovani A (2009) TIR8/SIGIRR: An IL-1R/TLR family member with regulatory functions in inflammation and $\mathrm{T}$ cell polarization. Trends Immunol 30(9): 439-446.

28. Suzanne C Segerstrom, Gregory E Miller (2004) Psychological stress and the human immune system: A meta-analytic study of 30 years of inquiry. Psychol Bull 130(4): 601-630.

29. Raison CL, Miller AH (2003) When not enough is too much: The role of insufficient glucocorticoid signaling in the pathophysiology of stressrelated disorders. Am J Psychiatry 160(9): 1554-1565.

30. Pace TW, Hu F, Miller AH (2007) Cytokine-effects on glucocorticoid receptor function: Relevance to glucocorticoid resistance and the pathophysiology and treatment of major depression. Brain Behav Immun 21(1): 9-19.

31. Dowlati Y, Herrmann N, Swardfager W, Liu H, Sham L, et al. (2010) A meta- analysis of cytokinesin major depression. Biol Psychiatry 67(5): 446-457.

32. Xavier RJ, Podolsky DK (2007) Unravelling the pathogenesis of inflammatory bowel disease. Nature 448(7152): 427-434.

33. Charalambous BM, Stephens RC, Feavers IM, Montgomery HE (2007) Role of bacterial endotoxin in chronic heart failure: The gut of the matter Shock 28(1): 15-23.

34. Creely SJ, McTerman PG, Kusminski CM, Fisher M, Da Silva NF, et al. (2007) Lipopolysacharide activates an innate immune system response in human adipose tissue in obesity and type 2 diabetes. American Journal of Physiology-Endocrinology and Metabolism 292(3): 740-747.

35. Strober W, Fuss I, Mannon P (2007) The fundamental basis of inflammatory bowel disease. The Journal of Clinical Investigation 117(3): 514-521.

36. Rook GA, Lowry CA (2008) The hygiene hypothesis and psychiatric disorders. Trends in Immunology, 29(4): 150-158.

37. Chacon MR, Vendrell J, Miranda M, Ceperuelo Mallafre V, Megia A, et al. (2007) Different TNF-alpha expression elicited by glucose in monocytes from type 2 diabetes mellitus patients. Atheroscrelosis 194(2):18-25.

38. Engebretson S, Chertog R, Nichols A, Hey Hadavi J, Celenti R, et al. (2007) Plasma levels of tumor necrosis factor-alpha in patients with chronic periodontitis and type 2 diabetes. Journal of Clinical Periodontology $34(1): 18-24$

39. Koleva Goergieva DN, Sivkova NP, Terzieva D (2011) Serum inflammatory cytokines IL-1beta, IL-6, TNF alpha and VEGF have influence on the development of diabetic retinopathy. Folia Med (Povdiv) 53(2): 44-50.

40. Al Attas OS, Al Daghri NM, Al Rubeaan K, da SilvaNF, Sabico S L, et al. (2009) A.L. Changes in endotoxin levels in T2DM subjects on antidiabetic therapies. Cardiovascular Diabetology 8: 11-20.

41. Pussinen PJ, Havulinna AS, Lehto M, Sundvall J ,Salomaa V (2011) Endotoxemia is associated with an increased risk of incident diabetes. Diabetes Care 34(2): 392-397.

42. Tilg H, Moschen AR (2014) Microbiota and diabetes: An evolving relationship. Gut 63(9): 1513-1521.

43. Kroenke K, SpitzerR L, WilliamsJ B (2001) The PHQ-9: Validity of a brief depression severity measure. Journal of General Internal Medicine 16(9): 606-613.
44. Löwe B, Unützer J, Callahan C M, Perkins A J, Kroenke K (2004) Monitoring depression treatment outcomes with the patient health questionnaire-9. Medical Care 42(12): 1194-1201.

45. Löwe B, Schenkel I, Carney Doebbeling C, Göbel C (2006) Responsiveness of the PHQ-9 to Psychopharmacological Depression Treatment. Psychosomatics 47(1): 62-67.

46. Spitzer RL, Williams JB, Kroenke K, Hornyak R, McMurray J (2000) Validity and utility of the PRIME-MD patient health questionnaire in assessment of 3000 obstetric-gynecologic patients: the PRIME-MD Patient Health Questionnaire Obstetrics-Gynecology Study. American Journal of Obstetrics and Gynecology 183(3): 759-769.

47. Löwe B, Kroenke K, Herzog W, Gräfe K (2014) Measuring depression outcome with a brief self-report instrument: sensitivity to change of the Patient Health Questionnaire (PHQ-9). Journal of Affective Disorders 81(1): 61-66.

48. Cohen J (1988) Statistical power analysis for the behavioral sciences. 2nd ed Lawrence Erlbaum Associates, Publihers Hillsdale, NJ ISBN: 13: 978-0805802832.

49. Silverman MN, Pearce BD, Miller AH (2003) Cytokines and HPA axis regulation In Cytokines and mental health Kronfol Z: Kluwer Academic Publihers Boston, pp. 85-122.

50. Talbot F, Nouwen A (2000) A review of the relationship between depression and diabetes in adults: Is there a link? Diabetes Care 23(10): 1556-1562.

51. Bourdel Marchasson I, Helmer C, Barberger Gateau P, Peuchant E, Février $B$, et al. (2007) Characteristics of undiagnosed diabetes in community dwelling French elderly: The 3C study. Diabetes Res Clin Pract 76(2): 257-264.

52. Dankner R, Geulayov G, Olmer L, Kaplan G (2009) Undetected type 2 diabetes in older adults. Age \& Ageing 38(1): 56-62.

53. Nouwen A, Nefs G, Caramlau I, Connock M, Winkley K, et al. (2011) Prevalence of depression in individuals with impaired glucose metabolismo $r$ undiagnosed diabetes: A sistematic review and metaanalysis of the European Depression Indiabetes (EDID) Research Consortium. Diabetes Care 34(3): 752-762.

54. Pouwer F, Beekman AT, Nijpels G, Dekker JM, Snoek FJ, et al. (2003) Rates and risks for comorbid depression in patients with type 2 diabetes mellitus: results from a community-based study. Diabetologia 46(7): 892-898.

55. O Connor PJ, Crain AL, Rush WA, Hanson AM, Fischer LR, et al. (2009) Does diabetes double the risk of depression? Annals of Family Medicine $7(4): 328-335$.

56. Mirza S, Hossain M, Mathews C, Martinez P, Pino P, et al. (2012) Type 2-diabetes is associated with elevted levels of TNF-alpha IL-6 and adiponectin and low levels of leptin in a population of Mexican Americans: A cross-sectional study. Cytokine 57(1): 136-142.

57. Pickup JC, Chusney GD, Thomas SM, Burt D (2000) Plasma interleukin-6 tumour necrosis factor alpha and blood cytokine production in type 2 diabetes Life Sciences 67(3): 291-300.

58. Rytter E, Vessby B, Asgård R, Johansson C, Sjödin A, et al. (2009) Glycaemic status in relation to oxidative stress and inflammation in wellcontrolled type 2 diabetes subjects. Br J Nutr 101(10): 1423-1426.

59. Vinik AI (2005) The metabolic basis of atherogenic dyslipidemia Clinical Cornerstone 7(2-3): 27-35.

60. Wisse BE (2004) The inflammatory syndrome: The role of adipose tissue cytokines in metabolic disorders linked to obesity. Journal of the American Society of Nephrology 15(11): 2792-2800.

61. Cheung CMG, Vania M, Ang M, Chee SP, Li J (2012) Comparison of aqueous humor cytokine and chemokine levels in diabetic patients with and without retinopathy. Molecular Vision 18: 830-837. 
62. Pradham AD, Manson JE, Rifai N, Buring JE, Ridker PM (2001) C-reactive protein, interleukin 6 , and risk of developing type 2 diabetes mellitus. JAMA 286(3): 327-334.

63. Thorand, Löwel H, Schneider A, Kolb H, Meisinger C, et al. (2003) $\mathrm{C}$-reactive protein as a predictor for incident diabetes mellitus among middle-aged: Results from the MONICA Augsburg cohort study, 19841998. Archives of Internal Medicine 13(1): 93-99.

64. Vozarova B, Stefan N, Hanson R, Lindsay RS, Bogardus C, et al. (2002) Plasma concentrations of macrophage migration inhibitory factor are elevated in Pima Indians compared to Caucasians and are associated with insulin resistance. Diabetologia 45(12): 1739-1741.

65. Bruehl H, Wolf OT, Convit A (2009) A blunted cortisol awakening response and hippocampal atrophy in type 2 diabetes mellitus. Psychoneuroendocrinology 34(6): 815-821.

66. Hackett RA, Steptoe A, Kumari M (2014) Association of diurnal patterns in salivary cortisol with type 2 diabetes in the Whitehall II study. Journal of Clinical Endocrinology and Metabolism 99(12): 4625-4631.

67. Lederbogen F, Hummel J, Fademrecht C, Krumm B, Kuhner C, et al. (2011) Flattened circadian cortisol rhythm in type 2 diabetes. Experimental and Clinical Endocrinology \& Diabetes 119(9): 573-575.

\section{ISSN: 2574-1241}

DOI: $10.26717 / B J S T R .2019 .13 .002437$

Ernesto Rosario Hernández. Biomed J Sci \& Tech Res

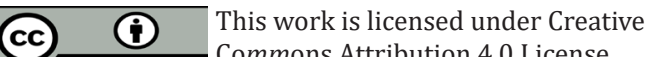

Submission Link: https://biomedres.us/submit-manuscript.php
68. Cameron OG, Thomas B, Tiongo D, Hariharan M, Greden JF (1987) Hypercortisolism in diabetes mellitus. Diabetes Care 10(5): 662-664.

69. Vermes I, Steinmeltz E, Schoorl J, van der Veen EA, Tilders FJ (1985) Increased plasma levels of immunoreactive B-endorfin and corticotropin in non-insulin-dependent. Lancet 2(8457): 725-726.

70. Chiodini I, Adda G, Scillatini A, Coletti F, Morelli V, et al. (2007) Cortisol secretion in patients with type 2 diabetes. Diabetes Care 30(1): 83-88.

71. Larsen N, Vogensen FK, van den Berg FW, Nielsen DS, Andreasen AS, et al. (2010) Gut microbiota in human adults with type 2 diabetes differs from non-diabetic adults. PLoS One 5(2): 9085.

72. WuX, Ma C, Han L, Nawaz M, Gao F, et al. (2010) Molecular characterization of the faecal microbiota in patients with type II diabetes. Current Microbiology 61(1): 69-78.

73. Munck A, Guyre PM, Holbrook NJ (1984) Physiological functions of glucocorticoids in stress and their relation to pharmacological actions. Endocrine Reviews 5(1): 25-44.

74. Moulton CD, Pickup JC, Ismail K (2015) The link between depression and diabetes: The search for shared mechanisms. Lancet Diabetes Endocrinology 3(6): 461-471.

$\begin{array}{ll}\text { BIOMEDICAL } & \text { Assets of Publishing with us } \\ \text { RESEARCHES } & \text { Global archiving of articles } \\ \text { - Immediate, unrestricted online access }\end{array}$

